\title{
A comparative-longitudinal study of action-control beliefs and school performance: On the role of context
}

\author{
Todd D. Little \\ Yale University, New Haven, USA
}

\author{
David F. Lopez \\ Bard College, Annandale-on-Hudson, USA
}

\author{
Gabriele Oettingen and Paul B. Baltes \\ Max Plank Institute for Human Development, Berlin, Germany
}

\begin{abstract}
In a previous cross-sectional study comparing East and West Berlin children (Oettingen, Little, Lindenburger, \& Baltes, 1994), we found that children in West Berlin had higher beliefs in their own performance potential than in East Berlin, but that the correlation between these personal agency beliefs and actual school performance was stronger in East Berlin than in West Berlin. In this study, we report on a three-wave longitudinal follow-up of the original samples wherein we examined the impact of change in the East Berlin education system, which adopted the West Berlin system between the second and third measurement occasions. As expected, we found that the context change did not affect the East Berlin children's (grades 2-5, $n=198$ ) lower mean levels of agency beliefs; however, the changes did reduce the correlations between the beliefs and performance to the levels observed in West Berlin $(n=381)$.
\end{abstract}

After the 1989 fall of the Berlin Wall, we began a programme of research examining the role of school context in shaping children's action-control beliefs and their relations to school performance. In the initial study, we compared children educated in the former East Berlin with a matched sample from West Berlin (Oettingen, Little, Lindenberger, \& Baltes, 1994). We found two notable differences in this cross-sectional comparison between East and West Berlin children: (a) East Berlin children had lower personal agency and controlexpectancy beliefs than did West Berlin children, and (b) these beliefs about one's performance potential correlated more strongly with teacher's performance evaluations (i.e., the teacher-assigned course grades) in East Berlin than in West Berlin. Given our analysis of the schooling contexts, both outcomes were consistent with the East Berlin educational system's practices such as the pronounced emphasis on realistic self-evaluations (see Oettingen, 1995; Oettingen et al., 1994).

As part of the unification of Germany, the former East Berlin schools instituted the practices and formats of the West Berlin educational system at the beginning of the 1991-1992 school year. This change in the East Berlin educational context provided us with another quasi-experimental opportunity to conduct a comparative study on the role of context, this time utilising longitudinal methodology (Baltes, Reese, \& Nesselroade, 1977). In particular, we followed both samples during this transition (i.e., three times at yearly intervals), which allowed us to examine the question: Has the shift in school context affected the East Berlin children's action-control beliefs and their relations to teacher-related performance?

\section{The action-theory view of psychological control}

As measured in the Control, Agency, and Means-Ends Interview (CAMI; e.g., Little, Oettingen, \& Baltes, 1995a; Skinner, Chapman, \& Baltes, 1988), ${ }^{1}$ our tripartite actiontheory model is a specific and well-validated multidimensional view of psychological control (see Chapman, Skinner, \& Baltes, 1990; Little, 1998; Little et al., 1995a; Oettingen, 1995). The CAMI measures three categories of action-control beliefs. Each category reflects beliefs about the relations between an agent, various means or causes, and an end.

First, the causality related Means-Ends beliefs refer to children's generalised perceptions of the utility or causal power of a specific means (effort, ability, teachers, luck, and unknowns) in producing school outcomes (see Table 1 for sample items). These causality beliefs reflect children's naive theories of how school performance comes about (Little \& Lopez, 1997). Second, the self-related Agency beliefs, which are similar to efficacy beliefs (Bandura, 1997), refer to

\footnotetext{
${ }^{1}$ The revised instrument (Little et al., 1995a) is available on request.
}

Correspondence should be addressed to Todd Little, Department of Psychology, Yale University, P.O. Box 208205, New Haven, CT 06520-8205, USA.

These data were collected as part of a cross-national research project examining children's action-control beliefs of school performance conducted by the Action Control and Child Development project, codirected by Paul B. Baltes, Todd D. Little, and Gabriele Oettingen at the Max Planck Institute for Human Development and Education,
Berlin. We are grateful to the members of the Institute's Center for Lifespan Psychology and to several visiting scientists and external colleagues for many helpful discussions.

Acknowledgements of those involved with the East Berlin and West Berlin samples are detailed in earlier publications and thanked here again. Finally, we thank Werner Scholtysik and Wolfgang Assmann for their computer resource management services, as well as Matthias Graßhof, Anne Tschida, and Brigitte Wanner for their assistance. 
Table 1

Sample items from the Control, Agency, and Means-Ends Interview (CAMI)

\begin{tabular}{|c|c|}
\hline Means category & Example item \\
\hline \multicolumn{2}{|c|}{ Means-Ends beliefs (general or causality-related and means-specific) } \\
\hline Effort & Doing well in school—is that because kids really try hard? \\
\hline Ability & When kids get bad grades, is that because they're no good at school? \\
\hline Luck & Is doing well in school a matter of luck? \\
\hline Teachers & Do kids do well in school because their teachers help them? \\
\hline Unknowns & When kids get good grades in school, is it hard to know why? \\
\hline \multicolumn{2}{|c|}{ Agency beliefs (personal and means-specific) } \\
\hline Effort & I can really pay attention in class. \\
\hline Ability & I am just not very smart at school work. \\
\hline Luck & I would say that I am unlucky in school. \\
\hline Teachers & I have teachers who will help me when I want them to. \\
\hline \multicolumn{2}{|c|}{ Control expectancy (personal and means unspecified) } \\
\hline (unspecified) & If I want to do good at school, I can. \\
\hline
\end{tabular}

Note: Items are responded to on a 4-point scale: 1, never; 2, sometimes; 3, often; 4, always. Each of the 10 action-control dimensions is measured by six items, except controlexpectancy which has four items. See Little et al. (1995a) for the complete instrument as well as full validity and psychometric information.

children's beliefs that they personally possess or have access to performance-relevant means (i.e., effort, ability, teachers, and luck). Agency beliefs reflect children's personal judgements of their own performance potential. Last, Control Expectancy refers to children's overall expectations of being personally able to produce a desired outcome without specifying any means (Little, Oettingen, Stetsenko, \& Baltes, 1995b; Oettingen et al., 1994). These three categories of beliefs are referred to, collectively, as action-control beliefs: five dimensions of means-ends beliefs, four dimensions of agency beliefs, and a general control-expectancy.

\section{Action-control beliefs and school performance: Prior research}

Our prior research has focused primarily on the strength (mean levels) of children's action-control beliefs and on the relations of these beliefs with teacher-rated academic performance. We have found both important similarities and systematic differences in the nature of the action-control beliefs across various sociocultural contexts (for overviews, see Little, 1998; Oettingen, 1995). For example, children's means-ends or causality beliefs are very similar in the diverse socioeducational contexts we have examined (e.g., US, German, Japanese, and Russian samples; Little \& Lopez, 1997; Little et al., 1995b; Oettingen et al., 1994; Stetsenko, Little, Oettingen, \& Baltes, 1995). Such similarities indicate a "world view" equivalence in children's conceptions of the causal factors involved in school performance (i.e., their subjective theories of how school performance comes about). In interpreting these similarities, we presume that fundamental features of school contexts, in conjunction with cognitive developmental acquisitions and motivational processes, contribute to the high similarity in the means-ends beliefs. Such school-related features include general educational goal structures, the underlying model of teacher-based instruction, and basic educational learning principles (Little \& Lopez, 1997; Stetsenko et al., 1995).

Our initial comparison of East and West Berlin showed that children in both parts of Berlin also shared similar views of the factors that produce school performance even before German unification (Oettingen et al., 1994). In particular, these children shared nearly identical beliefs about the general causes or determinants of school performance (i.e., meansends beliefs). For example, in both settings, the difference in the children's ratings of the importance of effort and ability as causes of school performance was quite small (with ability lower than effort) in comparison to the other sociocultural contexts we have studied (e.g., Russia, Japan, United States) and the correlation between these ratings was much higher than in our other non-German samples (see Little \& Lopez, 1997, for details). Not only were the mean levels and intercorrelations among the means-ends beliefs similar in East and West Berlin, but so too were the correlations between these general causality-related conceptions and teacher-rated performance. As expected, these correlations were quite low ( $r s$ generally were zero or very weak; Oettingen et al., 1994; see also Little et al., 1995b).

In contrast to the very similar means-ends conceptions, we have found systematic differences in the mean levels of the children's agency and control-expectancy beliefs and in their relations to teacher-rated performance. First, we found that West Berlin children had higher mean levels of personal agency and control expectancy than did their East Berlin peers (i.e., at Time 1; see Oettingen et al., 1994). In fact, East Berlin children have shown the lowest levels of personal agency and control expectancy of the sociocultural contexts we have studied whereas US children have shown the highest levels (e.g., Little et al., 1995b). This cross-cultural variability is quite pronounced given that the mean levels are uniformly above the midpoint (see Little, 1998).

The second difference was in the correlations between the children's agency beliefs and their teacher-rated performance. In the initial comparison of the two Berlin contexts, we found that the East Berlin children's beliefs showed higher correspondence with their school marks than did the West Berlin children's beliefs. In other words, East Berlin children's appraisals of their own personal agency appears to relate more 
readily with the evaluations of their teachers than do the appraisals of the West Berlin children (Oettingen, 1995; Oettingen et al., 1994). Generally, the magnitudes of these relations have ranged from somewhat weak in US samples (i.e., $r$ s around .3; Little et al., 1995b; Multon, Brown, \& Lent, 1991) to quite strong in the Berlin samples (i.e., $r$ s between approximately .5 and .7; Oettingen et al., 1994). For example, at the first time of measurement in the current East Berlin sample, the self-related agency beliefs shared nearly $49 \%$ of the reliable variance with teacher-rated performance. Only $15 \%$ of the variance was shared in a comparable US sample (Little et al., 1995b).

Our framework for interpreting both the mean level differences and the correlational differences in agency and control-expectancy beliefs has focused on proximal features of the educational contexts (Oettingen et al., 1994; for theorising on the link between cultural values, educational context, and processes of efficacy appraisal, see Oettingen, 1995). In particular, we have emphasised how school-related features such as feedback transparency (publicly vs. privately expressed performance evaluations), feedback directness (supportive and esteem-protective vs. critical and realistic performance evaluations), and teaching strategies (degree of uni- to multidimensionality of the classroom format) are consistent with the systematic differences we have observed (Little et al., 1995b; Oettingen et al., 1994). Although our interpretational framework is, admittedly, only one of many that could be offered, the overall consistency of findings across all types of belief and sociocultural contexts lends considerable strength to the framework (for a review, see Little, 1998).

\section{East and West Berlin before unification}

As detailed by Oettingen et al. (1994), the nature of the feedback and the teaching strategies differed between the East and West Berlin contexts. An explicit educational goal in East Berlin focused on realistic or "adequate" self-evaluations, while the educational philosophy in West Berlin focused on transmitting factual knowledge to the children and refrained from offering a state-defined value system (for detailed reviews of the relevant literatures, see Oettingen, 1995; Oettingen \& Little, 1993; Oettingen et al., 1994). In other words, a central goal of the educational philosophy in East Berlin was to foster, in all students, the ability to evaluate themselves accurately and adequately (i.e., according to the judgement of the teacher). These differences in the overarching goals of the educational systems, yielded specific differences in the practices of teachers across the two school settings.

Regarding the nature of the feedback, performance evaluations in East Berlin schools were given from the first grade on, whereas, in West Berlin, graded evaluations were not given until the end of the second grade. Student evaluations were given in front of the whole class (i.e., the "class collective") in East Berlin, whereas more privacy was targeted in West Berlin. In East Berlin, public self-evaluations were encouraged, whereas in West Berlin schools, children's performance records were secured and not discussed in public forums such as parent-teacher assemblies. Given their educational goal differences, then, East and West Berlin schools differed in their relative emphasis on public (transparent) feedback.

In addition to the teacher's performance feedback, teaching strategies in East Berlin were more unidimensional (Rosenholtz \& Rosenholtz, 1981; Rosenholtz \& Simpson, 1984) than in West Berlin. Children of a given grade level in East Berlin schools received exactly the same materials, tasks, and pace of studying, irrespective of the children's interests or potential. Moreover, teachers were required to strictly adhere to the curriculum guidelines. In West Berlin, teaching strategies were less unidimensional (i.e., task, materials, and pacing were more varied) and teachers were allowed to accommodate to the individual needs of the children to a greater extent than in East Berlin (for detailed reviews of the relevant literatures, see Oettingen, 1995; Oettingen \& Little, 1993; Oettingen et al., 1994).

In our view, both feedback transparency and teaching strategies would influence the degree of social comparison opportunities. In our previous studies, such influences on the social comparison opportunities of the classroom environment (e.g., low in the United States, moderate in West Berlin, and high in East Berlin) appear to have constrained the beliefsperformance correlations across these sociocultural contexts (low in the United States, moderate in West Berlin, and high in East Berlin; see Little et al., 1995b). In a similar manner, both feedback transparency and directness (e.g., low in the United States, moderate in West Berlin, and high in East Berlin) appears to have constrained the mean levels of the self-related beliefs across these sociocultural contexts (high in the United States, moderate in West Berlin, and low in East Berlin; see Little et al., 1995b).

Hypotheses regarding the change in the East Berlin children's educational context. Given the findings of our earlier study (i.e., compared with West Berlin children, East Berlin children had lower agency and control-expectancy beliefs, but higher correlations between the beliefs and performance; Oettingen et al., 1994), we examined whether the East Berlin children continued to show the same mean level and correlational patterns after the change in educational context (i.e., after instituting the West Berlin administration and educational curriculum). In our view, the change in schooling context between Times 2 and 3 reflects a powerful quasi-experimental manipulation because the first two assessments of the East Berlin children provide a baseline for the third. As part of the change, new principals and administrators entered the East Berlin schools in order to institute the West Berlin educational policies and curriculum. Although the teachers were the same, they were required to adopt the new curriculum and educational practices which included less publicly and directly communicated evaluations and a more multidimensional classroom structure than before.

We expected the differences between East and West Berlin that were observed at the first occasion (1990; Oettingen et al., 1994) to mostly replicate at the second occasion (1991) because the East Berlin children were still being taught under the original system, even though broad sociopolitical changes were already under way at the macrosocial level. At the third occasion (1992), on the other hand, we expected the effects of the educational changes to emerge. In particular, although we hypothesised that the East Berlin children's agency and control-expectancy beliefs would remain stable (i.e., at the same mean levels), we expected that the magnitude of their beliefs-performance correlation would become lower and closer to their West Berlin agemates and we expected the West Berlin correlation to remain stable at each occasion. 
We base these expectations on two lines of reasoning. First, the social comparison processes, which are used to gauge one's standing relative to others in any given situation (i.e., a primary basis for the beliefs-performance correlations), depend on the particular circumstances and make-up of the immediate environment (Butler, 1992; Schmitz \& Skinner, 1993). In this regard, the procedural and structural changes instituted in the East Berlin context at the beginning of the school year that preceded the third time of measurement should circumscribe the accuracy with which the children could assess their relative positions. Switching from public-based to private forms of performance feedback and from unidimensional to more multidimensional classroom structures would limit such social comparison opportunities. This reduction in social comparison opportunities should reduce the correlational nexus between the children's beliefs and their teacher-rated school performance.

Regarding the second line of reasoning, children's perceptions of their personal levels of agency and control expectancy hinge on relatively more enduring processes such as cumulative experiences of successes and failures (Skinner, 1995). In our view, the change in context would not yet provide sufficient new experiences to initiate an increase in the mean levels of the East Berlin children's agency and control-expectancy beliefs to the levels of the West Berlin children. Therefore, we did not expect any systematic changes in the mean levels of the beliefs after only one year under the new schooling system.

In summary, although we did not exclude that some minor fluctuations may occur in the mean levels of the agency and control-expectancy beliefs, we expected the mean level patterns to remain generally stable over time. In contrast, because the change in educational context (e.g., shifting from strict unidimensional to relaxed unidimensional instructional formats and public to private performance feedback) should provide a sufficient reordering or "fine-tuning" of the individual-difference standings in the East Berlin context, we expected the beliefs-performance correlations would be reduced to the levels exhibited in the West Berlin context.

\section{Methods}

Participants. The samples consisted of all children who participated in at least two times of measurement. Thus, 198 East Berlin children (grades 2-5, 106 boys and 92 girls; tested in spring of 1990, 1991, 1992) and 381 West Berlin children (grades 2-5, 167 boys and 214 girls; tested in spring of 1991, 1992, 1993) participated. For both samples, approximately $50 \%$ of the children participated in all three measurement occasions while the remainder participated in at least two of the measurement occasions. Missing data and outliers were estimated using the saturated regression techniques we have used before (see Little et al., 1995b; Lopez \& Little, 1996). Although the amount of missing data $(16.7 \%$ of the whole sample) is meaningful, we emphasise here that all effects were verified on the nonmissing data. Moreover, our detailed supplemental analyses of imputation effects (Graham \& Hofer, 2000), selectivity effects (Little, Lindenberger, \& Maier, 2000), and drop out effects indicated no meaningful trends or patterns, supporting our imputation of the missing data.

Within both East and West Berlin, the samples were drawn from two schools serving middle to lower-middle class neighbourhoods and reflect educational contexts (Oettingen et al., 1994) that were typical of East and West Berlin. ${ }^{2}$ Analyses of possible between-school differences on the constructs showed very few and unsystematic mean level and correlational differences (Little et al., 1995a), indicating that the constructs' within-sample variability is small in comparison to the characteristic between-sample differences already evinced between the East and West Berlin children at Time 1 (Oettingen et al., 1994).

Instruments. We used the revised CAMI (Little et al., 1995a) to assess the children's action-control beliefs; however, because: (a) the means-ends beliefs were nearly identical at the first time point; (b) supplementary analyses showed that they were still as similar at Times 2 and 3; and (c) they have minimal correlations with course grades (e.g., Oettingen et al., 1994), we examined only the agency and control-expectancy beliefs. Finally, we used the children's school grades for math and verbal skills as indices of school performance. This measure reflects teachers' assessments of the children's performance in their math and language courses. The 6-point scale used in the former East Berlin during the first two time points was adjusted to a 5-point scale using the adjustment formula detailed in Oettingen et al. (1994). This transformation allows us to compare the means and standard deviations of the grades across the two samples; we found no betweensample differences on the means or variances (all $p s>.20$ ). The correlations with all other measures were not affected by the transformation.

\section{Analytical procedures}

We used multiple-group mean and covariance structures (MACS) analyses (Little, 1997) with LISREL (Jöreskog \& Sörbom, 1993). In addition to advantages such as disattenuation, tests of measurement equivalence, and inclusion of covariates, MACS models are well suited to examine crosstime similarities and differences in the mean levels and correlations among the constructs (McArdle, 1996). We representated each CAMI construct with three parcelled indicators (two items per indicator) according to the instrument's coding guidelines (Little et al., 1995a). Our extensive research with the instrument (e.g., Little \& Lopez, 1997; Little et al., 1995b; Oettingen et al., 1994) supports our selection of these indicators for these constructs (see also Little, Lindenberger, \& Nesselroade, 1999). In addition, we controlled for the effects of gender and the linear and quadratic effects of grade level in school. For a detailed report on the gender effects in these and our other samples, see Stetsenko, Little, Gordeeva, Grasshof, and Oettingen, in press. For the developmental effects, we found no systematic effects on the agency and control expectance beliefs; however, see Little and Lopez (1997) for the developmental trends associated with the causality beliefs.

Although our analysis procedures control for unreliability, we mention here that the reliability of each construct was sound (around .75 and above for each construct in each setting; see Little et al., 1995a, for details) and the stabilities were also sound: For achievement, the cross-time correlations

\footnotetext{
${ }^{2}$ In addition to socioeconomic and educational factors, these two samples were matched on age rather than historical time of measurement. Given the stability of the West Berlin system (and our results, see later), such a matching is justifiable for this comparison.
} 
(raw metric) were .90 and .91 in East Berlin and .86 and .88 in West Berlin; for the agency beliefs in effort, they were .69 and .81 in East Berlin and .60 and .69 in West Berlin; for ability, they were .71 and .81 in East Berlin and .61 and .72 in West Berlin; for luck, they were .75 and .77 in East Berlin and .61 and .68 in West Berlin; for teachers, they were .46 and .53 in East Berlin and .53 and .54 in West Berlin; and, finally, for the control expectancy, they were .54 and .69 in East Berlin and .53 and .66 in West Berlin. The stabilities in East Berlin for effort, ability, and luck were significantly higher than in West Berlin (all $p$ s $<.05)$.

We assessed model fit with the nonnormed (NNFI) and incremental fit indices (IFI) for which values above .9 are generally considered acceptable (Little, 1997). To test our hypotheses, we treated each time of measurement as a separate group (i.e., a six-group MACS analysis in which all unneeded cross-time parameters were not represented). ${ }^{3}$

\section{Results}

In line with our basic questions, we report our findings in two sections. First, we examine the mean level patterns and, second, we examine the correlational differences between the samples at each time point in order to evaluate the influence of educational context changes in East Berlin. Before turning to these results, however, we emphasise that the constructs demonstrated measurement equivalence across the three times of measurement and in both sociocultural contexts (NNFI = .945 and IFI $=.954)$. Following Little (1997), we defined measurement equivalence by constraining the loadings and intercepts to equality across the samples, but allowed the latent parameters to vary freely. Given the high levels of fit for this model, it indicates that the constructs are measurementequivalent in each group and at each time point, and, therefore, the resulting latent information can be validly compared.

\section{The effects of context change: Cross-time mean level and correlational patterns}

Mean level differences. Figure 1 shows the constrained mean levels that resulted from our hypothesis testing approach for the agency and control-expectancy beliefs $\left(\chi_{(20, n=579)}^{2}=\right.$

\footnotetext{
3 We examined the cross-sample and cross-time concordance of the correlations and mean levels in a general two-step process. First, we specified our expected pattern of similarities and differences. For the West Berlin sample, we expected cross-time equivalence (i.e., no changes) in the mean levels of each corresponding belief and in each respective beliefs-performance correlation. For the East Berlin sample we expected: (a) no changes for the mean levels at each occasion; (b) no changes in the beliefs-performance correlations at the first two occasions; but (c) a drop in the correlations at Time 3 that would equal the West Berlin magnitudes. We compared these restrictions, as a nested-model comparison, to an unconstrained form of the model. If the comparison yielded a significant difference (multivariate $p<.05$ ), we relaxed any constraints based on modification indices, fitted residuals, the estimates, and the standard errors until the multivariate $p$-value was greater than a .05 level. We chose this type of modelling because: (a) it reflects a strong test of our hypotheses; (b) it yields a clear and parsimonious representation of the data that reproduces the observed data as well as a freely estimated representation; and (c) any remaining differences reflect a substantial univariate drop in fit such that for a given construct nonidentical estimates are different $(p<.01)$. Comparative raw data and complete reliability and validity information is presented in Little et al. (1995a).
}

28.7, $p=.09$; for comparison purposes, the unconstrained raw data estimates are presented in Appendix 1). In examining Figure 1, note that those mean levels for a given construct that are not identical are significantly different $(p<.01)$. These mean level ratings reflect: (a) the degree to which the children believe that they have access to or can utilise their personal action-control resources to perform well in school, and (b) their general expectation for school success.

As expected, the mean levels of the East Berlin children's agency and control-expectancy beliefs remained stable across the three measurement occasions. In addition and as shown in our earlier work (Oettingen et al., 1994), at the first occasion East Berlin children had lower personal agency and controlexpectancy than did West Berlin children. Because the beliefs remained stable in East Berlin, this difference persisted at Times 2 and 3, even though three unexpected changes emerged $(p<.01)$ in West Berlin. At Time 3, when the sample was two years older than at Time 1, the West Berlin children, who did not experience dramatic changes in their schooling context, showed an increase in their agency for effort and teachers and in their general control expectancy. Although the source of this increase in the West Berlin children is difficult to trace, it may reflect a context by age-cohort interaction; however, and most important, the lower mean levels of the East Berlin context did not show this age-related increase.

Given that only three of the 30 mean levels diverged from our expectations (and only in the West Berlin context), the findings indicate that the mean levels of the East Berlin children's beliefs remained quite stable across all three times of measurement, even though they had begun learning under the West German educational system after the second occasion.

Correlational differences. Figure 2 displays the constrained disattenuated correlations between the agency and controlexpectancy beliefs and teacher-assigned school marks that emerged from our hypothesis testing procedures $\left(\chi^{2}(22, n=579)\right.$ $=21.9, p=.47)$. As with the mean level analyses, those correlations that are not identical are significantly different $(p<.01$; for comparative purposes, the raw data correlations are presented in Appendix 2). The correlations reflect the degree of correspondence between the children's beliefs in their own performance potential and their actual school performance.

Replicating our initial comparison, the East Berlin children showed higher correlations with School Marks than did West Berlin children at Times 1 and 2 (Oettingen et al., 1994). As we expected, however, at Time 3 (1992), after beginning the West Berlin teaching format, the East Berlin correlations were reduced, falling to the levels of the West Berlin correlations which were stable at each time point. This pattern supports our expectation that school-specific characteristics such as the manner of feedback (e.g., public vs. private) and the dimensionality of the classroom structure shape the degree to which children's beliefs conform to their teachers' performance evaluations, and that this effect emerged in a quite immediate manner. Given that the children had only been in the new educational context for one year, the changes in the correlational pattern are in marked contrast to the stability in the mean level patterns. Thus, as predicted: (a) the mean levels of the children's agency and control-expectancy beliefs were generally unaffected by the educational changes, 


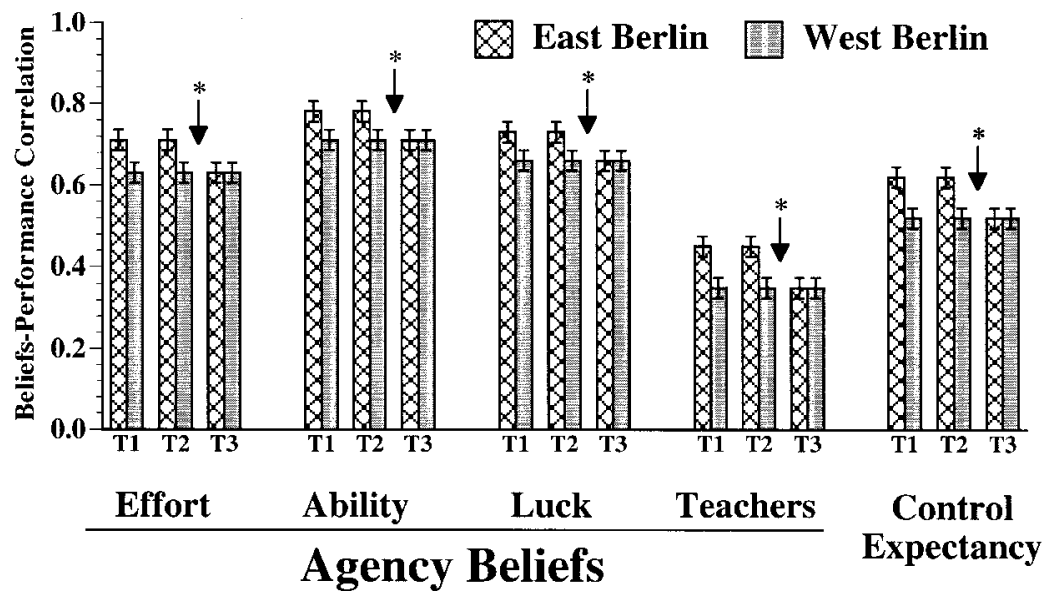

Figure 1. Constrained latent (disattenuated) mean levels of the children's personal agency and control-expectancy beliefs [Note: ${ }^{\star}$ Between Times 2 and 3, the East Berlin children began learning under the West German curriculum and administrative guidelines. These constrained mean levels do not differ from the unconstrained mean levels $\chi_{(20, n=579)}^{2}=28.7, p>.09$, and indicate that the mean levels showed very little change over time in either sample and were significantly lower in East Berlin than in West Berlin $(p<.01)$. That is, those mean-levels that are not identical for a given construct are significantly different, $p<.01$.]

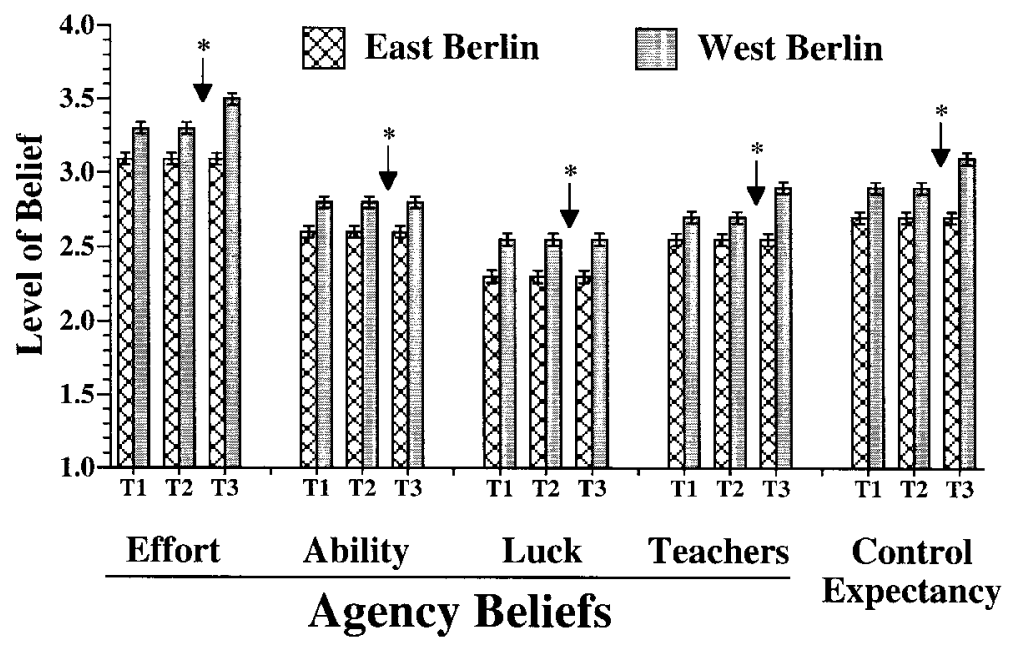

Figure 2. Constrained latent (disattenuated) correlations between the children's personal agency and control-expectancy beliefs and their teacher-assigned school marks [Note: ${ }^{\star}$ Between Times 2 and 3, the East Berlin children began learning under the West German curriculum and administrative guidelines. Estimated for each of the three occasions, these constrained correlations do not differ from the unconstrained correlations, $\chi_{(20, n=579)}^{2}=21.9, p>.35$. The results indicate that the correlations in the East Berlin sample were stable at the first two measurement occasions and became lower at Time 3, equalling the West Berlin correlations which remained stable at all three times of measurement. Those correlations that are not identical for a given construct are significantly different, $p<.01$.]

but (b) the correspondence between their actual school performance and their beliefs did change over time becoming equal to the levels of the West Berlin children at the third measurement occasion. Also note that the means-ends beliefs, which we did not include as part of these formal analyses, did not change over this time frame, both in terms of their mean levels and in terms of their correlations with performance. Moreover, in both samples, effort and ability are highly correlated aspects of school performance, suggesting that differential emphasis is not widely communicated in the respective school contexts (however, see Little \& Lopez, 1997, for rather striking differences when examined across other cultural contexts).

\section{Discussion}

Our study focused on changes in sociocultural and educational features and their effects on children's personal agency and control-expectancy beliefs about their school performance. The findings indicate that short-term changes in sociocultural and educational contexts can have a marked and quite immediate effect in shaping the degree of concordance between children's agency and control-expectancy beliefs and their teacher-assigned performance evaluations. In contrast, the strength (i.e., mean levels) of children's agency and control-expectancy beliefs appear relatively more robust to short-term changes. This finding suggests that longer-term 
changes to the contexts in which the children are embedded are needed before the strength of these beliefs would be influenced.

\section{The Effect of Context Change}

We have consistently found in our previous work that both the mean levels of the action-control beliefs and the links between these beliefs and teacher-rated performance can vary quite markedly as a function of sociocultural context (Little, 1998; Oettingen, 1995; Oettingen et al., 1994). We have interpreted the patterns of results with a framework that focuses on specific features of the children's proximal environment rather than on distal features such as social values (Little et al., 1995b; Oettigen, 1995; Oettingen et al., 1994). In particular, we have focused on school-related factors such as social transparency of performance feedback (private vs. public), directness of performance evaluations (critical vs. esteem-protective), and dimensionality of instructional format (unidimensional vs. multidimensional).

As mentioned earlier and detailed in other work (e.g., Oettingen et al., 1994), the East Berlin context can be characterised as possessing a generally public (i.e., transparent) feedback system, strongly critical and realistic performance evaluation practices, and a strongly unidimensional instructional format, whereas the West Berlin context can be characterised as having a generally private (i.e., nontransparent) feedback system, moderately critical and realistic performance evaluation practices, and a moderately unidimensional instructional format. These three features are not an exhaustive categorisation of the factors that can influence children's beliefs about their school performance. Moreover, we do not have direct measures of these features. We have chosen to highlight these possibilities because the patterns of similarities and differences across: (a) the various sociocultural contexts we have studied, and (b) the internal and external relationships among all the dimensions of action-control beliefs are consistently in line with the expectations we have derived using these features as our heuristic framework (see Little, 1998 , for a more detailed review of the supporting findings).

With this important caveat in mind, we have focused on these features as possible sources for the observed differences between East and West Berlin. For example, we have attributed the East Berlin children's lower mean levels of agency and controlexpectancy beliefs primarily to the differences in the degree to which teachers' feedback publicly, critically, and realistically addresses a child's academic capabilities. Similarly, we have attributed the East Berlin children's higher magnitude of correlation to the greater opportunities for accurate social comparisons found in the school's public feedback system and highly unidimensional teaching format. These putative sources for the observed East-West differences were involved in the transformations affecting the East Berlin context. The effects of the changes in educational context for the children of the former East Berlin (i.e., learning under the West Berlin administrative and curriculum formats) were pronounced and in accordance with our predictions.

The mean levels of the children's agency and control-expectancy beliefs. Despite the changes in educational context, the mean levels of the East Berlin children's agency and controlexpectancy beliefs remained largely stable. Consistent with the idea that action-control beliefs have a moderate disposi- tional character (e.g., Skinner, 1995), we found that East Berlin children: (a) showed no differences over time in the mean levels than their personal agency and control expectancy; and (b) continued to demonstrate lower mean levels than their West Berlin counterparts. In other words, the mean levels of the agency beliefs and the general control-expectancy remained mostly stable across time and the changes in educational context. A possible alternative explanation of the mean level stability in East Berlin is that although the structuralorganisational features changed, the in-class feedback and specific pedagogical styles of the teachers may not have changed in kind, thereby reinforcing and maintaining the strength (mean levels) of the beliefs.

Surprisingly, we found three increases in the mean levels of the West Berlin children's agency (effort and teachers) and control-expectancy beliefs at Time 3. As mentioned, these exceptions appear to reflect an age-cohort by context interaction in that they occurred only in the West Berlin context and at the third measurement, when the children were two years older than the initial comparison. However, the source of such an interaction is difficult to trace. We do not believe that the effect is maturational in nature because other longitudinal work (Little, Stetsenko, \& Maier, 1999) indicates that these beliefs actually decrease with age when the educational context is stable. This finding suggests that the teachers in West Berlin may have modified their style of in-class feedback. Unfortunately, we do not have data on the teachers that could support this conjecture and, thus, it can only be offered as a possible post-hoc explanation. Clearly, a further follow-up comparing these two educational contexts is needed to determine whether the mean level patterns would show more commonality once the structural features have been in place for longer than a single year.

The link between beliefs and teacher-rated performance. We view the beliefs-performance correlational patterns as supporting our assumption that proximal features of the school context shape the link between children's personal agency and controlexpectancy beliefs and their teachers' performance evaluations (Little et al., 1995b; Oettingen et al., 1994; Stetsenko et al., 1995). Given the baseline information inherent in longitudinal data, the changes in the size of the correlations following the change in the East Berlin children's educational context were very uniform. The consistent and sizeable shifts in correlation are punctuated by the stability of the beliefs-performance correlations during the first two occasions in East Berlin and all three occasions in the West Berlin context, which did not experience such dramatic changes. These changes highlight the context's role in shaping the link between children's agency and control-expectancy beliefs and their teacher-assigned school marks.

For the East Berlin children, changing from: (a) publicly communicated to privately communicated feedback, and (b) a highly unidimensional to a moderately unidimensional instructional format (see Oettingen et al., 1994) appear to have resulted in beliefs-performance correlations that were equal to the West Berlin baseline, whereas the West Berlin baseline remained stable. Although the cross-time stability of the beliefs and school grades were high, they still allowed sufficient room to "fine tune" the distribution of individual differences such that the beliefs-performance correlations dropped to West Berlin levels. These correlational changes are particularly noteworthy because they occurred at the end of the first year following the change in school context. Again, as mentioned, 
because we do not have direct measures of actual teacher behaviour or the associated changes in East Berlin schools, our interpretations must be viewed with some caution. For example, the switch from a 5-point grading system also coincides with the drop in correlation. Given the very high stability of the school grades and the fact that the 6-point scale of the first two measurement points contained a rarely used category, we feel that this explanation is unlikely. Instead, the consistency in the body of evidence emanating from our research programme, both cross-sectionally (e.g., Little et al., 1995b; Oettingen et al., 1994; Stetsenko et al., 1995) and longitudinally (see also Little et al., 1999), lends support to the interpretations based on our guiding framework.

The results of this study highlight two remaining issues that remain for future work with this framework. The first issue is whether the three explanatory mechanisms function independently or whether cumulative or interactive effects influence the nature of children's action-control beliefs about their school performance. To address this issue, direct measures of the explanatory features will need to be developed and implemented. The second issue focuses on the subjective nature of the performance measure that we used. Because of our attempts to capitalise on the historical events surrounding the unification of Berlin and the dramatic changes in Moscow, we were unable to develop objective performance measures across the various sociocultural contexts and, therefore, needed to rely on the one common performance measure in these contexts; namely, the teacher-assigned school grades. Future work in this framework will need to include objective performance measures in order to tease apart effects that are related to changes in the children's beliefs from those related to changes in the evaluation process.

In our view, answering our guiding questions has illuminated possible mechanisms shaping children's beliefs in their own personal agency. First, the mean levels of the agency and control-expectancy beliefs showed considerable stability, suggesting that the strength of such self-related beliefs may be more tenacious and more slowly affected by contextual changes (see also Skinner, 1995) than the link between such beliefs and school performance. The persistence of the mean level differences raises an important developmental question (Berry, 1989); namely, how long do the characteristic levels of the action-control beliefs prevail, given that the context in which they were initially formed has changed? Second, the links between children's agency and control-expectancy beliefs and their teachers' performance evaluations were quite sensitive to the contextual changes, highlighting the role of context in shaping and forming this link. In addition, this sensitivity appears to be related to differences in performance feedback and teaching structures-only one year after the change in educational context the beliefs-performance correlations dropped in East Berlin children becoming equivalent to their West Berlin counterparts. The malleable nature of the link between self-related beliefs and performance also has important developmental implications not only for childhood but also for the entire lifespan (Baltes \& Baltes, 1986). For example, given that age-contexts continuously change, the concordance between beliefs and performance may also fluctuate across the lifespan. The effects of such fluctuation on the dynamics of growth and decline, then, would be an important topic for future research (Baltes, 1987).

\section{References}

Baltes, P.B. (1987). Theoretical propositions of life-span developmental psychology: On the dynamics between growth and decline. Developmental Psychology, 23, 611-626.

Baltes, M.M., \& Baltes, P.B. (Eds.) (1986). The psychology of control and aging. Hillsdale, NJ: Erlbaum.

Baltes, P.B., Reese, H., \& Nesselroade, J.R. (1977). Life-span developmental psychology: Introduction to research methods. Hillsdale, NJ: Erlbaum.

Bandura, A. (1997). Self-efficacy: The exercise of control. New York, NY: Freeman.

Berry, J.M. (1989). Cognitive efficacy across the life span: Introduction to the special series. Developmental Psychology, 25, 683-686.

Butler, R. (1992). What young people want to know when: Effects of mastery and ability goals on interest in different kinds of social comparisons. Fournal of Personality and Social Psychology, 62, 934-943.

Chapman, M., Skinner, E.A., \& Baltes, P.B. (1990). Interpreting correlations between children's perceived control and cognitive performance: Control, agency, or means-ends beliefs? Developmental Psychology, 26, 246-253.

Graham, J.W., \& Hofer, S.M. (2000). Multiple imputation in multivariate research. In T.D. Little, K.U. Schnabel, \& J. Baumert (Eds.), Modeling longitudinal and multilevel data: Practical issues, applied approaches, and specific examples (pp. 201-218). Mahwah, NJ: Erlbaum.

Jöreskog, K., \& Sörbom, D. (1993). Lisrel 8 user's guide. Chicago, IL: Scientific Software International.

Little, T.D. (1997). Mean and covariance structures (MACS) analyses of crosscultural data: Practical and theoretical issues. Multivariate Behavioral Research, 32, 53-76.

Little, T.D. (1998). Sociocultural influences on the development of children's action-control beliefs. In J. Heckhausen \& C.S. Dweck (Eds.), Motivation and self-regulation across the life span (pp. 281-315). New York: Cambridge University Press.

Little, T.D., Lindenberger, U., \& Maier, H. (2000). Selectivity and generalizability in longitudinal research: On the effects of continuers and dropouts. In T.D. Little, K. U. Schnabel, \& J. Baumert (Eds.), Modeling longitudinal and multilevel data: Practical issues, applied approaches, and specific examples (pp. 187-200). Mahwah, NJ: Erlbaum.

Little, T.D., Lindenberger, U., \& Nesselroade, J.R. (1999). On selecting indicators for multivariate measurement and modeling with latent variables: When "good" indicators are bad and "bad" indicators are good. Psychological Methods, 4, 192-211.

Little, T.D., \& Lopez, D.F. (1997). Regularities in the development of children's causal conceptions of school performance. Developmental Psychology, 33, 165175.

Little, T.D., Oettingen, G., \& Baltes, P.B. (1995a). The revised control, agency, and means-ends interview (CAMI): $A$ multi-cultural validity assessment using mean and covariance (MACS) analyses (Materialen aus der Bildungsforschung, No. 49). Berlin: Max Planck Institute.

Little, T.D., Oettingen, G., Statsenko, A., \& Baltes, P.B. (1995b). Children's action-control beliefs and school performance: How do American children compare with German and Russian children? Fournal of Personality and Social Psychology, 69, 686-700.

Little, T.D., Stetsenko, A., \& Maier, H. (1999). Action-control beliefs and school performance: A longitudinal study of Moscow children and adolescents. International fournal of Behavioral Development, 22, 799-823.

Lopez, D.F., \& Little, T.D. (1996). Children's action-control beliefs and emotional adjustment in the social domain. Developmental Psychology, 32, 299-312.

McArdle, J.J. (1996). Current directions in structural factor analysis. Current Directions, 5, 11-18.

Multon, K.D., Brown, S.D., \& Lent, R. W. (1991). Relation of self-efficacy beliefs to academic outcomes: A meta-analytic investigation. Fournal of Counseling Psychology, 38, 30-38.

Oettingen, G. (1995). Cross-cultural perspectives on self-efficacy. In A. Bandura (Ed.), Self-efficacy in a changing society (pp. 149-176). New York: Cambridge University Press.

Oettingen, G., \& Little, T.D. (1993). Intelligenz und Selbstwirksamkeitsurteile bei Ost- und Westberliner Schulkindern [Intelligence and self-efficacy beliefs in East and West Berlin school children]. Zeitschrift für Sozialpsychologie [German fournal of Social Psychology], 24, 186-197.

Oettingen, G., Little, T.D., Lindenberger, U., \& Baltes, P.B. (1994). Causality, agency, and control beliefs in East versus West Berlin children: A natural experiment on the role of context. Fournal of Personality and Social Psychology, $66,579-595$.

Rosenholtz, S.J., \& Rosenholtz, S.H. (1981). Classroom organization and the perception of ability. Sociology of Education, 54, 132-140.

Rosenholtz, S.J., \& Simpson, C. (1984). The formation of ability conceptions: Developmental trend or social construction? Review of Educational Research, $54,31-63$. 
Schmitz, B., \& Skinner, E. (1993). Perceived control, effort, and academic performance: Interindividual, intraindividual, and multivariate time-series analyses. Fournal of Personality and Social Psychology, 64, 1010-1028.

Skinner, E.A. (1995). Perceived control, motivation, and coping. Thousand Oaks, CA: Sage.

Skinner, E.A., Chapman, M., \& Baltes, P.B. (1988). Control, means-ends, and agency beliefs: A new conceptualization and its measurement during childhood. Fournal of Personality and Social Psychology, 54, 117-133.
Stetsenko, A., Little, T.D., Oettingen, G., \& Baltes, P.B. (1995). Agency, control and means-ends beliefs in Moscow children: How similar are they to their Western peers? Developmental Psychology, 31, 285-299.

Stetsenko, A., Little, T.D., Gordeeva, T.O., Grasshof, M., \& Oettingen, G. (in press). Gender effects in children's beliefs about school performance: A crosscultural study. Child Development.

Appendix 1

Raw means and standard deviations of the variables used in the analyses

\begin{tabular}{|c|c|c|c|c|c|c|c|c|c|c|c|c|}
\hline \multirow[t]{3}{*}{ Variable } & \multicolumn{6}{|c|}{ East Berlin } & \multicolumn{6}{|c|}{ West Berlin } \\
\hline & \multicolumn{2}{|c|}{1990} & \multicolumn{2}{|c|}{1991} & \multicolumn{2}{|c|}{1992} & \multicolumn{2}{|c|}{1991} & \multicolumn{2}{|c|}{1992} & \multicolumn{2}{|c|}{1993} \\
\hline & Mean & $S D$ & Mean & $S D$ & Mean & $S D$ & Mean & $S D$ & Mean & $S D$ & Mean & $S D$ \\
\hline \multicolumn{13}{|l|}{ Agency beliefs } \\
\hline Effort & 2.88 & 0.49 & 2.96 & 0.50 & 2.95 & 0.48 & 3.07 & 0.48 & 3.08 & 0.44 & 3.14 & 0.47 \\
\hline Ability & 2.70 & 0.48 & 2.71 & 0.53 & 2.71 & 0.50 & 2.83 & 0.50 & 2.84 & 0.49 & 2.88 & 0.51 \\
\hline Teachers & 2.79 & 0.45 & 2.88 & 0.44 & 2.88 & 0.45 & 2.94 & 0.50 & 2.91 & 0.48 & 3.04 & 0.53 \\
\hline Luck & 2.58 & 0.48 & 2.57 & 0.49 & 2.58 & 0.44 & 2.74 & 0.50 & 2.72 & 0.45 & 2.69 & 0.45 \\
\hline Control & 2.78 & 0.57 & 2.78 & 0.58 & 2.80 & 0.54 & 2.90 & 0.62 & 2.87 & 0.57 & 2.91 & 0.59 \\
\hline \multicolumn{13}{|c|}{ Means-ends beliefs } \\
\hline Effort & 2.66 & 0.39 & 2.76 & 0.40 & 2.73 & 0.38 & 2.69 & 0.42 & 2.73 & 0.38 & 2.72 & 0.39 \\
\hline Ability & 2.39 & 0.42 & 2.41 & 0.43 & 2.39 & 0.39 & 2.43 & 0.46 & 2.44 & 0.41 & 2.38 & 0.38 \\
\hline Teachers & 1.89 & 0.46 & 1.88 & 0.47 & 1.91 & 0.42 & 1.82 & 0.44 & 1.79 & 0.42 & 1.80 & 0.47 \\
\hline Luck & 1.80 & 0.47 & 1.68 & 0.45 & 1.73 & 0.44 & 1.86 & 0.50 & 1.79 & 0.44 & 1.72 & 0.46 \\
\hline Unknowns & 2.32 & 0.46 & 2.19 & 0.39 & 2.26 & 0.40 & 2.20 & 0.46 & 2.22 & 0.43 & 2.18 & 0.38 \\
\hline Achieve & 2.99 & 0.81 & 3.00 & 0.90 & 3.01 & 0.88 & 3.04 & 0.84 & 2.99 & 0.87 & 3.02 & 0.88 \\
\hline
\end{tabular}

Note: The tabled values are raw means and standard deviations with effects of unreliability and differential validity of the indicators still present. The modelled values presented in Figure 1 are latent estimates with the effects of unreliability removed and the differential validities of the indicators accounted for. They are also the constrained values that emerge after the hypothesis testing. Finally, these sample statistics are essentially identical when calculated for only those individuals with complete data.

Appendix 2

Raw correlations with school grades for the variables used in the analyses

\begin{tabular}{lccccccc}
\hline Variable & \multicolumn{3}{c}{ East Berlin } & & \multicolumn{3}{c}{ West Berlin } \\
\cline { 2 - 3 } & 1990 & 1991 & 1992 & & 1991 & 1992 & 1993 \\
\hline Agency beliefs & .59 & .65 & .52 & .49 & .52 & .54 \\
$\quad$ Effort & .66 & .73 & .60 & .54 & .57 & .60 \\
Ability & .62 & .63 & .53 & .54 & .55 & .54 \\
Luck & .39 & .40 & .29 & .27 & .29 & .27 \\
Teachers & .46 & .47 & .41 & .36 & .41 & .42 \\
Control & & & & & & \\
Means-Ends beliefs & .12 & .23 & .21 & .17 & .16 & .27 \\
Effort & .11 & .19 & .00 & .19 & .14 & .17 \\
Ability & -.13 & -.11 & -.13 & -.06 & -.02 & .04 \\
Luck & -.20 & -.15 & -.28 & -.15 & -.17 & -.17 \\
Teachers & -.07 & -.11 & -.06 & -.05 & -.06 & -.01 \\
$\quad$ Unknowns & & & & & & & \\
\hline
\end{tabular}

Note: The tabled values are partial correlations (i.e., gender and the linear and quadratic effects of school grade). Because they are raw metric correlations, the effects of unreliability are still present. The modelled correlations presented in Figure 2 are latent correlations with the effects of unreliability removed and they are constrained values that emerge after the hypothesis testing. Finally, these sample statistics showed little and unsystematic differences when calculated for only those individuals with complete data and they varied only trivially when the control variables were not partialled. 